\title{
Akulturasi budaya Tembang Lir-ilir sebagai media dakwah Sunan Kalijaga
}

\author{
Rori Amelya Rumpaka, Lutfiah Ayundasari* \\ Universitas Negeri Malang, Jl. Semarang No. 5 Malang, Jawa Timur, Indonesia \\ *Penulis korespondensi, Surel: lutfiah.fis@um.ac.id
}

Paper received: 01-04-2021; revised: 15-04-2021; accepted: 30-04-2021

\begin{abstract}
Islam is mostly embraced by Indonesians. The majority of Indonesians adhere to the largest religion in the world. Islam entered the archipelago through peaceful channels in accordance with the religious mission, namely rahmatan li al-'ālamīn. Which is Islam as a religion that embraces or protects all people and other things. Likewise with the culture in Indonesia. Indonesian culture has existed since time immemorial. Various cultures passed on from their ancestors to their successors. Indonesia has a variety of cultural features that need to be preserved and maintained. This is what makes Indonesian society thick with culture. Islam entering Indonesian territory is not easy. Because the majority of people still adhere to and are thick with culture. Therefore, the figures who spread the religion of Islam must know the character of Indonesian society. Using the method of acculturating existing cultures in Indonesia with Islamic religious values is the right way to spread Islam.
\end{abstract}

Keywords: acculturation; culture; Islam

\begin{abstract}
Abstrak
Agama Islam dianut sebagian besar oleh masyarakat Indonesia. Mayoritas masyarakat Indonesia menganut agama yang dianut terbesar di dunia ini. Islam masuk ke wilayah Nusantara melalui jalur damai sesuai dengan misi agama yakni rahmatan li al-'ālamīn. Yang mana Islam sebagai agama yang merangkul atau mengayomi semua umat dan hal lainnya. Begitu pula dengan kebudayaan yang ada di Indonesia. Kebudayaan Indonesia sudah ada sejak dahulu kala. Beragam kebudayaan diwariskan para leluhur kepada penerusnya. Indonesia memiliki beragam corak kebudayaan yang perlu dilestarikan dan dijaga keberadaannya. Hal tersebut yang menjadikan masyarakat Indonesia kental akan budaya. Agama Islam masuk ke wilayah Indonesia tidak mudah. Dikarenakan mayoritas masyarakat masih menganut dan kental akan budaya. Maka dari itu, para tokoh penyebar agama Islam harus mengetahui karakter masyarakat Indonesia. Menggunakan cara mengakulturasi budaya yang ada di Indonesia dengan nilai-nilai agama Islam merupakan cara yang tepat untuk penyebaran agama Islam.
\end{abstract}

Kata kunci: akulturasi; budaya; Islam

\section{Pendahuluan}

Agama Islam merupakan ajaran yang dibawa oleh Nabi Muhammad SAW atas utusan Allah SWT. Rasulullah SAW menyebarkan dan mengajarkan agama islam kepada masyarakat Makkah dengan sepenuh hati, ikhlas, serta tidak menyerah walaupun masyarakat Makkah tidak menerima kehadiran beliau dan tetap menyembah berhala. Berbanding terbalik dengan Makkah, kota Madinah menerima dengan senang hati dan terbuka atas kehadiran Nabi Muhammad untuk mengajarkan agama Islam di kota mereka. Setelah Rasulullah wafat, penyebaran agama Islam tidak pernah berhenti. Kepimpinan umat Islam digantikan oleh para sahabat Nabi yakni para Khulafaur Rasyidin. Para sahabat Nabi yang menggantikan kepimpinan umat Islam untuk menyebarkan agama Islam yang ditunjuk sesuai dengan 
petunjuk Allah SWT. Kemudian Islam menyebar sampai penjuru dunia lainnya yang disebarkan oleh para Khalifah.

Penyebaran ajaran Islam memiliki misi yakni rahmatan li al-ālamīn, sehingga dapat diterima oleh masyarakat dengan mudah. Yang mana islam sebagai agama yang merangkul atau mengayomi semua umat dan hal lainnya. Ajaran Islam mengajarkan tentang aqidah, akhlaq, dan syariah, serta dalam Islam tidak memiliki perbedaan kelas atau kasta. Semuanya bersatu dan berdamai dalam satu naungan agama Islam. seperti yang dikatakan oleh Syafrizal (2015) bahwa "Selain ajaran aqidah dan akhlak agama Islam mulai mengembangkan ilmu pengetahuan seperti kedokteran, matematika dan ilmu alam lainnya. Semua itu berlandaskan atas dalil al Qur'an". Ajaran ini disebarkan melalui jalur perdagangan, pendidikan,bahkan budaya. Hal tersebut yang membedakan dengan ajaran agama yang lain yang menyebarkan melalui penjajahan.

Agama Islam masuk dan diterima oleh masyarakat Nusantara salah satunya melalui perdagangan dan pengakulturasian budaya. Seiring dengan meluasnya wilayah perdagangan, Islam mulai masuk ke wilayah Nusantara dan mulai tersebar ajarannya. Penyebaran Islam di Nusantara tidak dilakukan secara bersamaan, sehingga setiap wilayah di Nusantara mendapatkan banyaknya pengaruh yang berbeda-beda. Pada abad ke-15 sampai ke-16 M muncul kebudayaan baru di Jawa, yang mana diantara Kebudayaan Hindu-Buddha dan Kebudayaan Islam. Kebudayaan itu disebut dengan kebudayaan masa peralihan. Berdasarkan temuan bukti arkeologi, Anita (2014) yang dikutip dari Mustopo (2001) menyatakan bahwa bukti-bukti arkeologis Islam di daerah pantai dan pedalaman menunjukan bahwa apa yang digambarkan sebagai kebudayaan tersebut sebagian besar merupakan hasil dari kebudayaan Islam yang tumbuh dan berkembang secara bersamaan pada masa kejayaan hingga surutnya kerajaan Majapahit dan tumbuhnya Demak sebagai kesultanan Islam pertama di Jawa.

Kebudayaan yang ada di Jawa sangatlah beragam dan masyarakat sangat menghormati itu. Sehingga para tokoh penyebar agama Islam di Jawa memiliki dan menggunakan strategi untuk mengajarkan agama islam dengan menggunakan kebudayaan. Penyatuan kebudayaan Jawa dengan ajaran Islam digunakan sebagai strategi penyebaran ajaran Islam di Jawa. Secara perlahan, masyarakat Jawa menerima dan mengikuti ajaran Islam. Unsur kebudayaan lokal masih dipegang teguh oleh masyarakat dan diselaraskan dengan unsur-unsur islam. seperti yang dilakukan oleh para Wali di Jawa. Menurut beberapa ahli, Wali Jawa atau yang biasa disebut dengan Wali Songo ini merupakan tokoh penyebar agama Islam di pulau Jawa. Selanjutnya pada artikel ini akan dibahas mengenai masuknya Islam ke Jawa, akulturasi budaya Jawa dengan ajaran Islam, dan Penggunaan tembang lir-ilir sebagai media dakwah sunan Kalijaga.

\section{Metode}

Metode penelitian sejarah merupakan sebuah cara atau metode yang digunakan oleh peneliti sebagai pedoman dalam melakukan penelitian dalam peristiwa sejarah dan permasalahannya. Sebuah metode penelitian sejarah merupakan instrumen untuk melakukan rekonstruksi peristiwa sejarah menjadi sebuah cerita sejarah (Abdullah \& Surjomihaedjo, 1984).

Penulisan pada artikel ini menggunakan metode studi pustaka yang mengumpulkan dari berbagai sumber dan data dari berbagai buku-buku dan artikel-artikel. Teknik yang digunakan 
penulis dalam penulisan artikel ini adalah menggunakan analisis deskriptif dengan menggambarkan dan menjelaskan permasalahan dengan bentuk teks yang telah ditulis.

\section{Hasil dan Pembahasan}

\subsection{Masuknya Ajaran Islam Di Jawa}

Masuknya Islam ke Nusantara terdapat beragam teori dan sudut pandang dari para ahli sejarah. Terdapat lima teori tentang masuknya Islam ke Nusantara, yang pertama teori Arab. Pada teori ini menyatakan jika ajaran Islam langsung dibawa dan disebarkan oleh bangsa Arab sekitar abad ke-7 M. Bangsa Arab berperan penting dalam perdagangan dan ditemukan buktibukti sejarah yang menunjukkan telah adanya interaksi antara pedagang Arab, Cina, dan Nusantara yang memebuktikan Islam sudah mulai masuk ke wilayah Nusantara. Kedua, teori Cina yang menjelaskan bahwa etnis Cina Muslim sangat berperan dalam penyebaran agama Islam di Nusantara. Dengan adanya hubungan baik antara pedagang Arab Muslim dengan etnis Cina dikarenakan Muslim Arab dan Cina secara berbarengan datang ke Nusantaa untuk melakukan perdagangan. Teori ketiga adalah teori Persia. Pada teori ini lebih terlihat dari aspek bahasa Persia berpengaruh pada bahasa arab yang digunakan oleh masyarakat Nusantara. Keempat, teori India. Pada teori ini menyatakan jika Islam datang ke Nusantara tidak langsung dari bangsa Arab, namun melalui India pada abad ke-13. Teori ini juga mengatakan jika Islam berasaldri Gujarat, namun tidak sepenuhnya pernyatan dibenarkan. Teori yang terakhir adalah teori Turki. Teori ini mejelaskan jika selain dari bangsa Arab dan Cina, Nusantara juga mendapatkan ajaran Islam dari Turki. Dalam teori Turki ini juga menyatakan Nusantara diislamkan oleh orang Kurdi.

Islam masuk di Pulau Jawa melalui banyak jalur. Salah satunya adalah jalur perdagangan. Pelabuhan merupakan tempat berinteraksi antar pedagang dan menjadi pusat perdangan. Dikenal merupakan negara maritime yang diapit oleh dua samudera, Indonesia menjadi kawasan yang rmai menjadi tempat perdagangan ataupun hanya singgah yang ramai. Agama Islam masuk ke Nusantara dimulai dari daerah pesisir seperti Goa, Talo, Pasai, Gresik, Cirebon, Banten, dan Demak. Menurut Azra (2002) dalam menyampaikan mengenai Islam masuk ke Nusantara bahwa terdapat empat hal yang disampaikan historiografi tradisionalnya. Yang pertama, agama Islam dibawa langsung dari Tanah Arab ke Nusantara. Kedua, Islam diperkenalkan oleh para guru atau juru dakwah profesional. Ketiga, golongan masyarakat yang pertama kali masuk Islam adalah para penguasa. Dan yang keempat, kebanyakan para juru dakwah profesional datang di Nusantara pada abad ke-12 dan ke-13 untuk menyebarkan agama islam.

Dalam perkembangan Islam di Jawa mulai terjadi sekitar akhir abad ke-15 hingga awal abad ke-16. Hal tersebut dapat dilihat dari dua sisi. Yang pertama, ketika menjadi masa peralihan dari sistem politik Hindu-Buddha yang memiliki pusat pemerintahan di pedalaman Jawa Timur. Pusat pemerintahan tersebut dari berlokasi di daerah pedalaman Jawa Timur berpindah menjadi daerah pesisir utara Jawa Tengah. Dan yang kedua, sebagai puncak islamisasi yang dilakukan oleh para wali di Jawa. Pada masa penyebaran agama Islam, walisongo mendirikan masjid sebagai awal dalam proses penyebaran. Masjid digunakan sebagai tempat ibadah dan sebagai pusat tumbuh kembangnya kebudayaan Islam. Segala aktivitas yang dilakukan untuk proses penyebaran ajaran Islam. Seperti yang dikatakan oleh Soebardi \& Anthony Jhon (1976) yang dikutip oleh Anita (2014) bahwa Lembaga pesantren 
itulah yang paling menentukan watak keislaman dari kerajaan-kerajaan Islam dan yang memegang peranan paling penting bagi penyebaran Islam sampai pelosok-pelosok. Dari lembaga-lembaga pesantren itulah asal-usul sejumlah manuskrip tentang pengajaran islam di Asia Tenggara, yang tersedia secara terbatas. Untuk bisa benar-benar memahami sejarah Islamisasi di suatu wilayah, kita harus mempelajari berbagai lembaga pesantren tersebut, karena lembaga inilah yang menjadi anak panah penyebaran Islam di wilayah ini.

\subsection{Akulturasi Budaya Jawa dengan Ajaran Islam}

Sudah dijelaskan sebelumnya, Jawa merupakan salah satu pulau yang kaya akan tradisi dan kebudayaan yang ada di Indonesia. Hal tersebut terjadi karena jauh sebelum agama islam masuk ke wilayah Nusantara, agama Hindu-Budha dan kepercayaan primitif lainnya merupakan ajaran yang dianut oleh masyarakat Nusantara. Ajaran-ajaran tersebut sudah mempengaruhi berbagai aspek kehidupan masyarakat pada masa itu. Namun dengan datangnya ajaran dan kebudayaan baru tidak akan mempengaruhi ataupun menghilangkan kebudayaan yang sudah ada sebelumnya. Dengan masuknya Islam di Indonesia, menyebabkan terjadinya akulturasi (bercampurnya kebudayaan yang berbeda karena percampuran bangsabangsa dan saling mempengaruhi). Adanya percampuran kebudayaan akan melahirkan kebudayaan baru yaitu kebudayaan Islam.

Sebelum datangnya Islam di Indonesia, sudah banyak berdiri kerajaan-kerajaan yang bercorak Hindu-Buddha. Sebagai contoh adalah kerajaan Majapahit dan Sriwijaya. Kerajaan Majapahit mampu menaklukkan kerajaan-kerajaan kecil yang ada di pesisir utara Jawa. Daerah pesisir merupakan daerah perdagangan yang menjadi tempat masuknya agama Islam. Para pemimpin kerajaan tersebut memeluk agama islam dan menjadikan Islam sebagai senajata politik untuk melepaskan diri dari Majapahit. Menurut Al-Amri (2017) bahwa "Setelah runtuhnya Majapahit $1520 \mathrm{M}$; di daerah pesisir proses Islamisasi berjalan sangat intensif hingga akhirnya berdirilah kerajaan-kerajaan Islam seperti, Demak, Banten dan Cirebon. Namun dalam segi pemahaman aqidah Islam, tidak serta merta mantap, dan melenyapkan alam pikiran filsafat lama, seperti Hindu dan Budha".

Proses islamisasi di Indonesia tidak hanya melalui satu cara. Para ulama dan wali yang bertugas dalam menyebarkan agama Islam memiliki berbagai jalan untuk mengambil hati dan simpati dari masyarakat Jawa. Tidak akan meninggalkan kebudayaan sebelumnya. seperti yang dikatakan oleh Al-Amri (2017) jika dalam "proses islamisasi di Indonesia tidak berjalan satu arah, tetapi banyak arah atau melalui berbagai macam pintu. Pintu-pintu itu, misalnya melalui kesenian, pewayangan, perkawinan, pendidikan, perdagangan, aliran kebatinan, mistisisme dan tasawuf. Hal tersebut yang menyebabkan terjadinya kontak budaya dan sulit untuk dihindari jika unsur budaya lokal masuk dalam proses Islamisasi di Indonesia". Dalam akulturasi budaya Jawa berkomunikasi dalam bentuk struktur agama-sosial. Menurut Taufik Abdullah yang mana "Adapun relasi Islam dan budaya Melayu yang mengambil pola integrasi, dipahami bahwa Islam berkembang dan menjadi salah satu penyangga terpenting dalam struktur politik Melayu" (Abdullah, 1989).

Ketika agama islam berkembang, tidak akan pernah benar-benar sama dari satu tempat ketempat lainnya atau bahkan dari satu waktu ke waktu lainnya. Islam membentuk suatu tradisi kultural dari pandangan-pandangan yang terkait. Tradisi kultural ini akan berubah dan mengikuti sesuai dengan ruang lingkupnya. Seperti yang dikatakan Muqoyyidin (2013) bahwa 
"perspektif tersebut akan mengantarkan pada pemahaman bahwa relasi Islam dengan budaya lokal berlangsung dalam konstruksi apresiatif-akomodatif-afirmatif sehingga akan menampilkan wajah tradisi Islam yang beragam". Perspektif tersebut digunakan oleh para tokoh penyebar agama Islam di Jawa. Tokoh Walisongo memperkenalkan ajaran islam dengan menggunakan tradisi yang ada. Sehingga jika ingin mempelajarinya harus belajar tentang kearifan lokal juga. Salah satu contohnya adalah penggunaan kesenian wayang sebagai sarana dakwah dan pengenalan ajaran Islam. Padahal kesenian wayang ini merupakan bagian ritual dari ajaran Hindu Jawa sebagai seremonial. Pemanfaatan wayang sebagai sarana dakwah ini tidak akan mengkhawatirkan masyarakat karena mengancam tradisi, budaya, dan posisi mereka. Segala lapisan strata sosial masyarakat seperti, petani, pedagang, dan bahkan bangsawan telah diislamkan dengan cara ini.

\subsection{Penggunaan Tembang Lir-ilir sebagai Media Dakwah Sunan Kalijaga}

Seperti sudah dijelaskan diatas, penggunaan perspektif atau pendekatan kultural sebelumnya yang dilakukan oleh Walisongo sangatlah terbukti keberhasilannya. Ajaran Islam tersampaikan dengan lancar tanpa adanya peperangan dan kekhawatiran dari masyarakat. Salah satu dari kesembilan wali yang mengajarkan agama Islam di Jawa adalah Sunan Kalijaga. Beliau adalah pangeran Tuban yang bernama Tumenggung Wilatikta putra dari adipati Tuban. Sunan Kalijaga memiliki nama asli yakni Raden Said. Ia hidup diperkirakan dari akhir masa Majapahit sampai pada awal kerajaan Mataram. Anggota Walisongo yang bernama Raden Said ini turut merancang Masjid Agung Demak dan Masjid Agung Cirebon.

Sunan Kalijaga dalam hal berdakwah, beliau memiliki pola berdakwah hampir sama dengan guru sekaligus sahabat dekatnya, Sunan Bonang. Ia menggunakan kesenian dan kebudayaan yang sudah ada sebagai sarana dan pendekatan dalam berdakwah. Dengan adanya masyarakat Jawa yang masih memiliki kepercayaan dan pendirian yang kuat, ia menggunakan strategi yang selalu bersikap toleran pada budaya lokal. Secara perlahan dan bertahap ia mulai memperkenalkan ajaran Islam pada masyarakat. Semakin lama akan semakin terbiasa dan masyarakat mulai meninggalkan kebiasaan lamanya. Sunan Kalijaga selalu memperkenalkan agama Islam secara luwes dan tanpa menghilangkan culture atau kesenian daerah yang sudah ada sebelumnya. Beliau merupakan anggota Walisongo yang cukup terkenal pada masanya di kalangan para santri dan abangan. Santri menurut Geertz yang dikutip dalam Sumbulah (2012) adalah kelompok yang menjunjung tinggi doktrin keagamaan sert mengekspresikn keagamaannya melalui seni, etiket, pakaian, bahasa, dan mistik. Sedangkan Greertz mengatakan jika abangan merupakan kelompok bagi pra petani yang bergantung pada kelompok priyayi. Sunan Kalijaga terkenal dengan metode dakwahnya yang menggunakan seni ukir, wayang, gamelan, serta seni suara suluk. Karya seni suara suluk ini karya Sunan Kalijaga yang terkenal adalah tembang Lir-ilir.

Tembang Lir-ilir merupakan sebuah tembang Jawa yang diciptakan oleh Sunan Kalijaga yang dipergunakan untuk media dakwah Islam pada masyarakat Jawa. Tembang tersebut diciptakan sekitar abad ke-15 M. Beliau tidak hanya menciptakan tembang Lir-ilir saja, namun juga Kidung Rumekso in Wengi sebagai media dakwah juga. Lir-ilir memiliki makna utama menurut Ahmad Chodjim (2003) dalam Paaneah, dkk (2019) yaitu "mengajak masyarakat untuk menjalani hidup dengan lebih taat kepada Allah SWT, memaksimalkan kehidupan untuk ma'rifat bil Allah (mengenal Allah secara mendalam) dan tidak hanya sekedar untuk mengajak masyarakat agar memeluk agama Islam". Secara tersirat, tembang Lir-ilir mempunyai makna 
keseluruhan mengenai keimanan dalam agama Islam, seperti rukun islam, pertaubatan, muhasabah (memahami diri sendiri tentang kebaikan dan keburukan yng telah diperbuat), serta memperbaiki kesalahan jika masih ada waktu sebelum ajal menjemput.

Pada setiap syair dari tembang Lir-ilir memiliki makna tersendiri bagi kehidupan manusia secara syariat islam. Menurut Setiyaningsih (2015) bahwa Sunan Kalijaga memiliki cara untuk menerjemahkan ajaran Islam menajadi rangkaian syair dan tembang pendek yang memiliki makna mendalam mengenai perlunya seseorang dalam memperhatikan hidup kita di dunia ini. Jangan hanya mementingkan hal-hal keduniawian melainkan berorientasikan pada kehidupan dalam alam kekekalan yaitu akhirat. Sehingga kehidupan dunia dan akhirat harus seimbang. Sunan Kalijaga mengingatkan bahwa kita mempunyai pertanggungjawaban pribadi kepada Tuhan, Karena semua perbuatan kita akan dimintai pertanggungjawaban dari kita. Sunan Kalijaga menawarkan Islam sebagai jalan dan bekal untuk menghadapi dan pertanggung jawabkan di hari akhir. Dengan berbekal mengenai keislaman dengan Rukun Imannya senantiasa melakukan hal-hal yang baik dan menjauhi hal-hal yang buruk (Mulyono, 2020).

Seperti yang diketahui, Sunan Kalijaga adalah salah satu anggota Walisongo yang dikenal sebagai sosok yang cerdas dan bijaksana. Dia merupakan satu-satunya anggota Walisongo yang asli keturunan Jawa. hal tersebut yang menjadikan beliau dalam menyebarkan agama Islam menggunakan cara tradisi Jawa, yang pada saat itu masyarakat masih terpengaruh oleh budaya Hindu.

\section{Simpulan}

Bangsa Indonesia merupakan negara yang sebagian besar penduduknya beragama Islam. Hal tersebut terjadi karena peran dari para ulama dan para tokoh penyebar agama Islam di Nusantara terdapat banyak teori dalam proses masuknya ajaran Islam di Nusantara. Masuknya ajaran Islam melalui berbagai jalur seperti perdagangan, perkawinan, dan juga perngakulturasian budaya. Pengislamisasian di Nusantara dimulai sekitar abad ke-13 M. Dengan adanya jalur perdagangan, daerah pesisir merupakan daerah yang disinggahi oleh berbagai macam bangsa untuk berdagang. Hal tersebut yang menyebabkan ajaran Islam mulai masuk ke Nusantara. Masyarakat Jawa khususnya pada saat itu masih terpengaruh dengan budaya Hindu. Sebelum datangnya agama Islam, Jawa sudah banyak kerajan-kerajaan yang berdiri dengan corak agama Hindu-Buddha. Peran para ulama dan Tokoh penyebar ajaran Islam sangat berpengaruh bagi kehidupen masyarakat Jawa. Salah satunya peran Walisongo, yang dipercaya sebagai tanda telah terjadi pengislamisasian masyarakat Jawa. Salah satu anggota Walisongo yang merupakan asli keturunan Jawa menggunakan strategi dalam proses penyebaran ajaran Islam pada masyarakat. Beliau tahu betul pada tradisi dan budaya Jawa. Hal tersebut yang menjadikan ia menyatukan ajaran Islam dengan kebudayaan yang sudah ada sehingga terciptanya ajaran atau kebudayaan baru, yaitu kebudayaan Islam. Dengan kecerdasannya, beliau menciptakan syair yang digunakan sebagai media dakwah dalam menyebarkan agama Islam. Tembang Lir-ilir merupakan salah satu media dakwah dari Sunan Kalijaga untuk mengajarkan Islam pada masyarakat. Makna dari syair tembang Lir-ilir tersebut adalah mengajak masyarakat untuk menjalani hidup dengan lebih taat kepada pencipta-Nya, memaksimalkan kehidupan untuk ma'rifat bil Allah (mengenal Allah secara mendalam), tidak hanya sekedar untuk mengajak masyarakat agar memeluk agama Islam. Penyebaran agama Islam di Nusantara memiliki misi yakni rahmatan li al-ālamīn, sehingga dapat diterima oleh masyarakat dengan mudah. Yang mana islam sebagai agama yang merangkul atau mengayomi semua umat dan hal lainnya. Dengan pengakulturasian budaya yang dilakukan oleh Sunan 
Kalijaga, beliau mengajarkan ajaran agama baru namun tidak menghilangkan budaya dan tradisi yang sudah ada sebelumnya. Sehingga masyarakat tidak akan khawatir akan kehilangan tradisi dan budaya lamanya. Proses penyebaran juga secara bertahap dan tidak terburu-buru, sehingga semakin lama masyarakat akan terbiasa dengan ajaran dan budaya baru dan melupakan ajaran lamanya.

\section{Daftar Rujukan}

Abdullah, T. (1989). Tradisi dan Kebangkitan Islam di Asia Tenggara. Jakarta: LP3ES.

Abdullah, T., \& Suryomihardjo, A. (Eds.). (1985). Ilmu Sejarah dan Historiografi: Arah dan Perspektif. Jakarta: Gramedia.

Al-Amri, L., \& Haramain, M. (2017). Akulturasi Islam Dalam Budaya Lokal. KURIOSITAS: Media Komunikasi Sosial dan Keagamaan, 10(2), 87-100.

Anita, D. E. (2016). Walisongo: Mengislamkan Tanah Jawa (Suatu Kajian Pustaka). Wahana Akademika: Jurnal Studi Islam dan Sosial, 1(2), 243-266.

Azra, A. (2002). Islam nusantara, jaringan global dan lokal. Bandung: Mizan.

Mulyono, M. (2020). Strategi Pendidikan Dalam Tembang Lir-Ilir Sunan Kalijaga Sebagai Media Dakwah Kultural. Tadbir: Jurnal Manajemen Dakwah, 5(1), 51-64.

Muqoyyidin, A. W. (2013). Dialektika Islam dan Budaya Lokal Jawa. IBDA: Jurnal Kajian Islam dan Budaya, 11(1), 1-18.

Paaneah, D. Z., Sunardi, S., \& Wuryani, E. (2019). Pemahaman syair Tembang Lir-Ilir karya Sunan Kalijaga dalam pembelajaran IPS pada siswa kelas VII B SMP Kristen Satya Wacana Salatiga. Satya Widya, 35(2), 140-147.

Sumbulah, U. (2012). Islam Jawa dan akulturasi budaya: karakteristik, variasi dan ketaatan ekspresif. elHarakah, 14(1), 51-68.

Syafrizal, A. (2015). Sejarah Islam Nusantara. Islamuna: Jurnal Studi Islam, 2(2), 235-253. 